\title{
Roentgenogran of the Issus
}

\section{Neurofibromatosis 환자에서 併發된 滲出性胸膜炎 및 右側胸壁에 생긴 腫塊}

\author{
연세대학교 의과대학 내과학 교식 \\ 하 성 규·임 승 길·김 성 규 \\ 병리학 교실 \\ 김 태 승 \\ 江西病院 外科 \\ 심 호 식
}

증 례

본 환차는 18 세 여자로서 약 15일간의 우측훙부 훙통 및 훙벽의 종괴를 주소로 연세의대부속 세브란스병원 내과에 입원하였다. 환자는 약 2 개월전 개인병원에서 결핵성 홍막염 으로 진단된후 본 병원에서 입원 가료한 바 있다(Fig. 1). 이당시 전신에 다발성의 cafe au lait spot 이 있었으며 좌측하지에 있는 종양의 생 검 결과는 neurofibroma였으며, 같이 시행한 늑막천자는 exudate

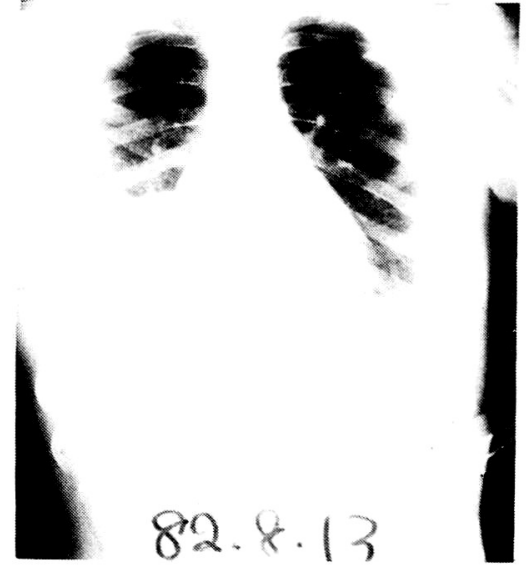

Fig. 1. Pleural effusion in the right lower lung field
의 소견을 보였고 임파구가 많아 결핵성 홍막염 진단 하에 항결핵제를 처방받고 퇴원하였으나, 증세의 호전 이 없었다. 입원 15일전부터 우측 홍통 및 홍벽의 종 괴가 점차 커짐을 주소로 입원하였다.

입 원당시 이학젹 소견상 혈압은 $110 / 70 \mathrm{mmHg}$, 맥박 82 회/분, 체온은 $38.6^{\circ} \mathrm{C}$ 였으며 우하부폐야에 둔탁도 증가와 호홉음 감소가 있었다. 경부 임파선은 촉지되 지 않았다. 입원당시 검사실 소견은 혈색소가 $11.9 \mathrm{~g}$ /

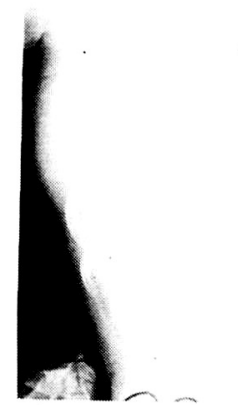

Fig. 2 Chest PA was taken on secona aumission. This film showed hazy density suggestive of huge tumor in the right lower lung field and lateral chest wall was bulged out 


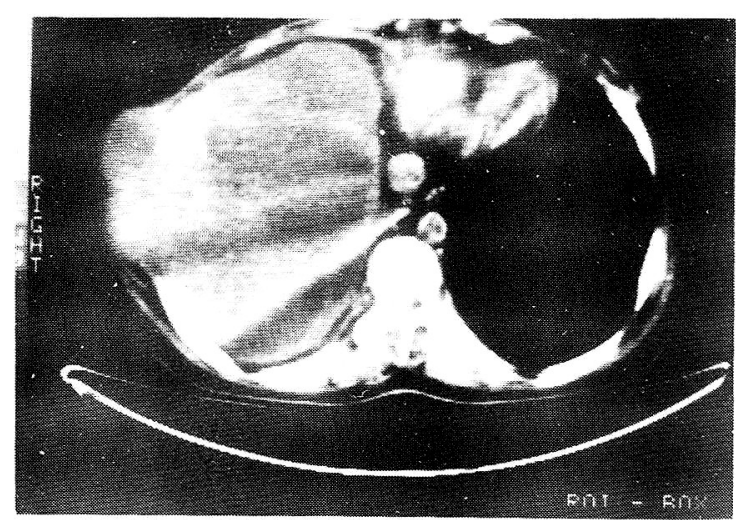

Fig. 3. CT scan revealed huge mass density of infiltrative type

$\mathrm{dl}$, 백혈구 $11,600 / \mathrm{mm}^{3}$ (중성구 $69 \%$, 임파구 $24 \%$ )이 었고, 간기능 검사 및 $\mathrm{BUN}$, creatinine 은 모두 정상 범주였다. 입원시 활영한 홍부 $\mathrm{X}$-선 소견상 우하부 폐 야에 균일성의 hazy density 가 보여, 폐염과 흉막액 이 병발한 소견이었으며, 우하엽의 종괴를 의심케도 하였다 (Fig. 2). 결핵피부 반응검사 (5 TU)는 음성이

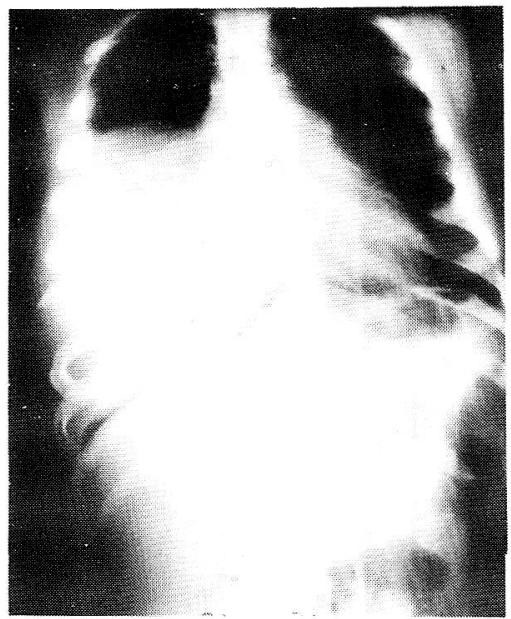

Fig. 4. Diagnostic pneumoperitoneum revealed that mass was localized to the supra-diaphragmatic region.

었다. 입원 4일째 시행한 Chest C-T scan 은 우하엽 부의 거대한 종양을 선명하게 보이고 있으며 훙벽의 종괴와도 연결되어 있음을 나타내고 있었다 (Fig. 3). 입원 7일째 Vim Silverman needle 을 사용하여 경피 적 생검을 시행하여 조직검사상 neurofibroma 가 나왔 으며, 입원 9 일째 좀 더 큰 조직을 얻기 위하여 우측

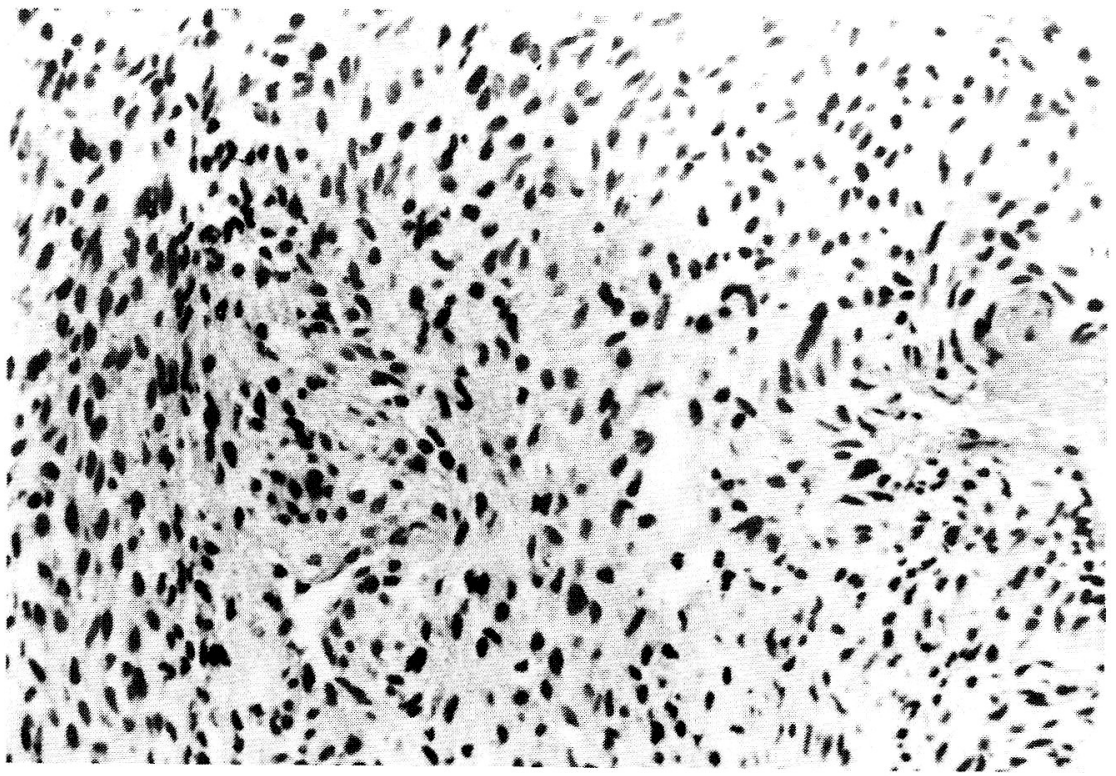

Fig. 5. The tumor is composed of weavy spindl cells (H-E. $\times 209)$ 


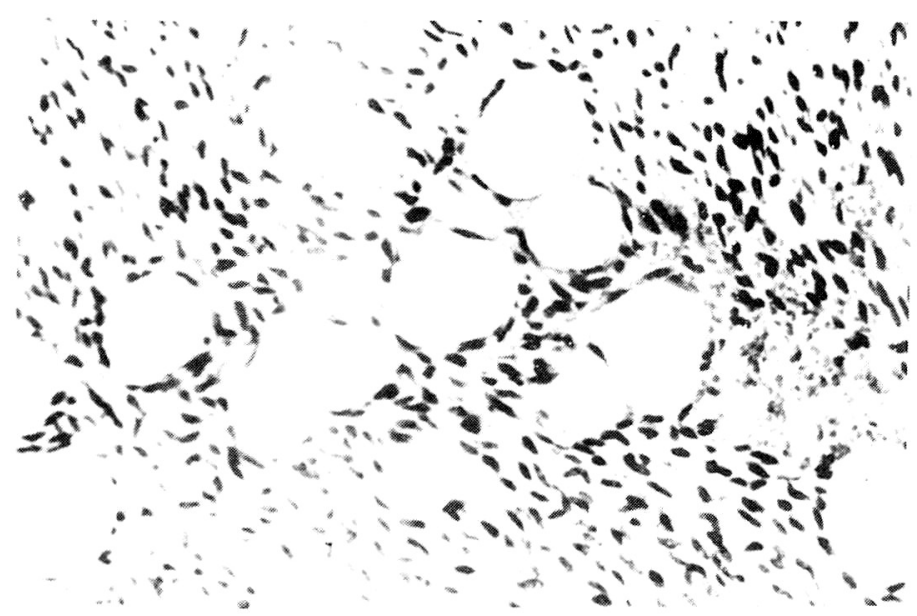

Fir. 6. The spindle tumor cells show infiltrative growth into subcutancous fat tissue $(\mathrm{H}-\mathrm{E}, \times 200)$.

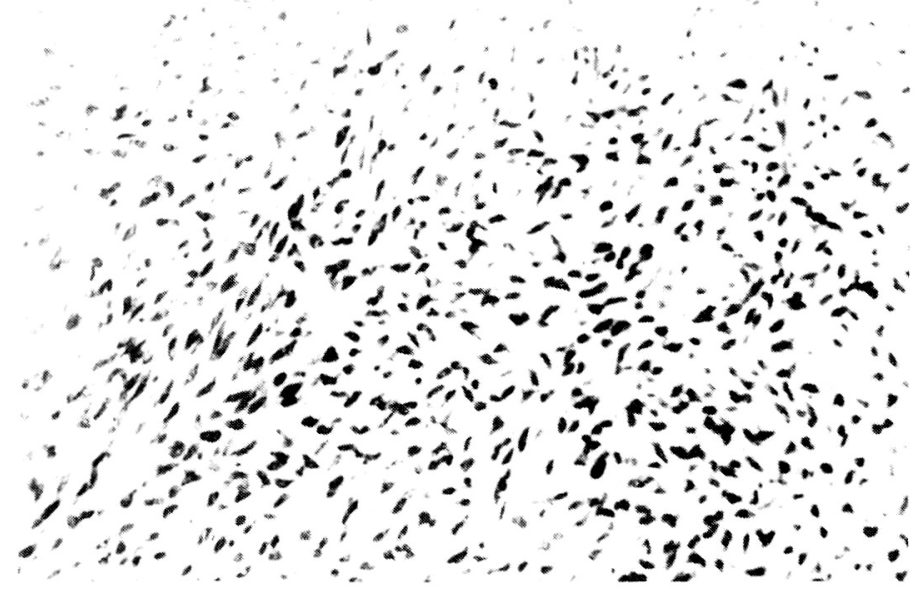

Fig. 7. The spindle tumor cells show infiltrative growth into skeletal muscle $(H \cdot E, \times 200)$.

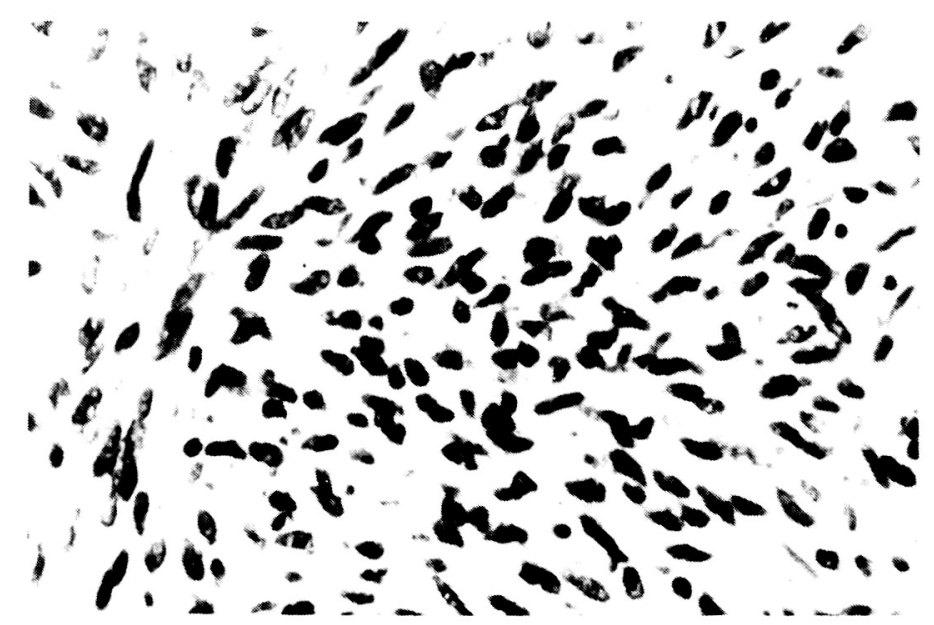

Fig. 8. The tumor cells have spindle cytoplasm and hyperchromatic nuclei There are several mitosis $(\mathrm{H} \cdot \mathrm{E}, \quad \times 400)$. 
Table 1. Areas and types of involvement in neurofibromatosis

\section{Skin}

Neurofibromas

Cafe au lait spots

Axillary freckling

\section{Skeleton and sof tissue}

Kyphoscoliosis

Posterior vertebral body scalloping

Skull defects

Bony erosion from tumor

Ribbon deformity and notching of ribs

Primary marginal defects of long bones

Intraosseous cystic lesions

Congenital bowing and pseudoarthrosis of tibia

Elephantiasis neuromatosa, verrucous or villous skin hypertrophy

Neurofibromas

Subperiosteal hemorrhage and cysts

\section{Central nervons ststem}

Intracranial tumors

Intraspinal tumors

Aqueductal stenosis and hydrocephalus

Syringomyelia

Vascular ststem

Vessel-wall hyperplasia

Microaneurysms

Renal artery stenosis and/or abdominal aortic coarctation with hypertension

Retroperitoneal hemorrhage

Mesenteric arterial insufficiency

Intracranial arterial occlusive disease

Cerebrovascular developmental anomalies

\section{Ophthalmic}

Pulsating exophthalmos

Sinuous deformity of eyelid border

Glaucoma

Schwannoma and malignant melanoma of choroid Optic nerve glioma

Sectoral retinal pigmentation

\section{Intrathoracic}

Pesterior mediastinal neurofibromas and meningoceles

Interstitial pulmonary fibrosis

Idiopathic hypertrophic subaortic stenosis

Gastrointestinal

Neurofibromas

Carcinoid

Juvenile polyposis coli

Urinary tract

Neurofibromas of bladder

Neurogenic bladder

Retroperitoneal neurofibromas affecting ureters

\section{Endocrine system}

Pheochromocytoma

Sipple's syndrome

Reduced fertility

Hyperparathyroidism

Hypoglycemia from insulinoma

Myxedema

Obesity

Precocious or retarded sexual development

Goiter

Diabetes insipidus

Table 2. Local Disease Control by Method of Initial Treatment

\begin{tabular}{lccc}
\hline Treatment & Number of patients & $\begin{array}{c}\text { Number of not } \\
\text { controlled or recurred }\end{array}$ & Number of local control \\
\hline Local Excision & 6 & 4 & 2 \\
Local Excision + XRT & 7 & $4^{*}$ & 3 \\
Local Excision+Chemotherapy & 1 & 0 & 1 \\
Radical Resection & 3 & 1 & 2 \\
Redical Resection+ & 3 & 0 & 3 \\
$\quad$ XRT+Chemotherapy & 20 & $9(45 \%)$ & $11(55 \%)$ \\
\hline$\quad$ Total & XRT & & \\
\hline
\end{tabular}

* patients died at surgery. XRT: Radiotherapy 
훙부 종기에서 외과적 생점을 시행하였다. 입원 10 일 째 횡경막 및 간장의 유착여부를 보기위하여 diagnostic pneumoperitoneum 을 시행하였다(Fig. 4).

\section{고 안}

본 증례는 우하측 폐야에 보이는 폐염, 훙막염 멏 우 측측벽에 생긴 egg size 의 종괴를 주소로 입원하였던 neurofibromatosis 환자에서 늑막천자, 늑막생 검 Chest CT Scan 및 조직생검등을 시행한바 neurogenic sarcoma 로 확진된 예였다. Neurofibromatosis 는 1849년 Smith 에 의해 기술되었고 1882년 Von Recklinghausen 에 의해 multiple skin lesion 과 subcutaneous tumor 를 가진 2예가 보고되면서 Von Recklinghausen's disease 라는 명칭이 붙게되었다 ${ }^{1)}$. 이 질환은 autosomal dominant trait 로 유전되지만 sporadic case 로도 보 고되고 있다. 발생빈도는 $2,500 ~ 3,300$ 출생 에 1 명 꼴로 나타나며 남자에 많은 것으로 되어있달. Brasfield 등ㄱ 에 의하면 직경이 $1.5 \mathrm{~cm}$ 이상인 cafe au lait spot 을 6 개 이상 가지고 있으면 가족력이 없더라도 neurofibromatosis 의 진단조건이 될 수 있다고 하였다. Neurofibromatosis 는 임상양상이 다양하여 여러 기관을 침범 할 수 있고 여러가지 질환과 동반하여 나타날 수 있는 데 나타날 수 있는 부위 및 동반질환을 보면 제 1 표 와 같달.

Neurofibromatosis 의 암종합병 증 2,3$)$ 을 보면 sarcomatous degeneration 이 가장 흔하고 많아서 $2.4 \%$ 부 터 $29 \%$ 까지 다양하게 보고되고 있으며 성 장속도가 빠 르거나 주위장기로 침윤의 증거가 있으면 악성화를 의 심하여야 한다. 한편 국소충격(local trauma)에 의한 악성화 경향이 증가한다는 보고도 있기 는 하나 Preston 등ㄱ)은 141예의 neurofibroma 생검후 의의있는 악성화 경향의 증가를 발견하지 못했다고 한다. 일단 sarcomatous degeneration 이 일어난 종양은 방사선치료에 저항이 매우 크므로 광범위한 종양의 절제 만이 유일하 게 환자를 구하는 길이되므로 악성종양의 의심이 있으 면 즉시 조직생검을 시행하여 확인하여 야 한다 ${ }^{3)}$. 한편 glioma, meningioma, pheochromocytoma, 갑상선의 medullary carcinoma 가 동반될 수 있으며 여러가지 다른 종류의 악성종양의 빈도가 증가되는 것으로 보고 되었는데 ${ }^{3)}$, Brasfield 등 ${ }^{1)}$ 에 의하면 110 명의 neurofibromatosis 환자중 유방암이 $9 \%$, 악성 흑색종이 $5.4 \%$, 갑상선암이 $3.6 \%$, 폐암이 $0.9 \%$ 에서 동반되었다고 한 다. Hammond 등5)은 neurofibromatosis 환자에서 sarcmoatous degeneration 을 조기에 발견할 수 있는 방법 으로 $\mathrm{Ga}^{67}$ Scanning 을 권장하고 있는데 $\mathrm{Ga}^{67}$ 은 폐암, 호지킨씨병, 악성흑색종, 간암, 고환 암등의 여러가지 악성종양과 대부분의 sarcoma 에서 친화성이 있는 성질 을 이용한 것이다. Storm등6)에 의하면 1957년부터 19 77년까지 20년동안 neurofibrosarcoma 로 치료받은 20 명의 환자를 치료방법, 국소재발의 빈도, 전이, 생존 율등으로 나누어 분석하여 보았는데 20 명중 14 명 (70\%) 에서 neurofibromatosis 가 동반되어 있었고 최초 치 료방법에 의한 국소재발의 빈도를 보면 제 2 표와 같다. American Joint Committee Clinical Staging에 따른 5 년 생존율을 보면 Stage I a 환자는 1 명 중 1 명, Stage II 환자는 9명 중 5 명, Stage III환자는 5 명중 2명, Stage unknown 환자는 5 명중 1 명이었다. 아울러 원격전이는 local control 후에도 자주 발생하여 $44 \%$ 에서 있었고 수술후 보조적 항암요법이필 요할 것 으로 생 각된다고 하 였다. 본 증례는 neurofibromatosis 가 있으면서 Chest CT Scan 상에서 우측 훙벽으로 침 윤된 우하엽의 종괴 를 확인하고 조직생검을 통하여 neurogenic sarcoma 로 진단된바 병리소견을 보면 방추형의 세포들로 구성 되어 있는 종양세포들이 피하지 방조직 및 골격근 사이로 침윤성 성장을 보이면서 핵은 농염 (hyperchromatic) 되어있고 핵분열상을 보여 neurogenic sarcoma 에 합 당한 소견을 보였다(Fig. 5,6,7,8). 한편 김등기이 지 적한바대로 횡경막 상하기관의 유착여부를 알기 위하여 시행한 diagnostic pneumoperitoneum 소견에 따르면 간장과의 유착은 없어 횡경막상부의 질환임을 확인 할 수 있었으나 특히 훙벽으로의 침윤이 있어 외과적절제 를 할 수 없었으며 방사선치료나 화학요법은 시행키에 적합치 않아 적절한 치료시기를 놓쳤던 증예였음을 부 언한다. 
$=$ Abstract $=$

Neurofibromatosis, massive pleural effusion and buldging mass on the right chest wall

Sung Kyu Ha, M.D. Seung Kil Lim M.D. and Sung Kyu Kim, M.D.

Department of Internal Medicine, Yonsei University, College of Medicine

Tae Seung Kim, M.D.

Department of Pathology, Yonsei University, College of Medicine

Ho Shik Shim, M.D.

Kang Seo Hospital

Neurofibromatosis is a rare syndrome characterized by abnormal cutaneous pigmentation and numerous skin tumors. Although the syndrome was previously described by Smith in 1849, Von Recklinghausen reported two cases of multiple skin and subcutaneous tumors in 1882 and was the first to recognize their neural origin. The protean manifestations of neurofibromatosis often not fully appreciated. Various tumors developed with this disease but sarcomatous degeneration of neurofibroma was the most common findings.

We reviewed clinical findings of 18 year-old female patients who was suffered from right lateral chest pain and buldging mass on the right chest wall. Sarcomatous degeneration of neurofibromatosis was confirmed by open biopsy.

\section{REFERENCES}

1) Brasfield RD. and Das Gupta TK.: Von Recklinghausens disease; A clinicopathological study. Ann Surg 175:86 104, 1972.

2) Barone DA: Neurofibromatosis. A clinical overview. Postgraduate Medicine. 66:73 82, 1979.

3) Pantoja E, Llobet RE, and Taveras JE.: Neoplastic complications of neurofibromatosis. Cutis, 22:677 680, 1978.

4) Preston FW, Walsh WS, and Clarke TH.:
Cutaneous neurofibromatosis. Arch Surg 64: 813 827, 1952.

5) Hammond JA, and Driedger AA.: Detection of malignant change in neurofibromatosis(Von Recklinghausen's disease) by Gallium 67 Scanning. Can Med Ass Journal 119:352 353, 1978.

6) Storm FK, Eilber FR, Mirra J, and Morton DL.: Neurofibrosarcoma. Cancer 45:126 129, 1980.

7) 金誠圭 : Pneumoperitoneum 의 진단적 이용. 最新 醫學 25:1167 1170, 1982. 